OPEN ACCESS

Edited by: Sandra Olga Brizga, Brizga Environmental, Australia

Reviewed by: Brian Douglass Richter, Sustainable Waters, United States Nicola Grigg, CSIRO Land and Water, Australia

*Correspondence: Meegan Judd meegan.judd@latrobe.edu.au

Specialty section:

This article was submitted to

Freshwater Science,

a section of the journal

Frontiers in Environmental Science

Received: 26 May 2021 Accepted: 10 January 2022 Published: 10 February 2022

Citation:

Judd M, Bond N and Horne AC (2022)

The Challenge of Setting "Climate Ready" Ecological Targets for Environmental Flow Planning. Front. Environ. Sci. 10:714877. doi: 10.3389/fenvs.2022.714877

\section{The Challenge of Setting "Climate Ready" Ecological Targets for Environmental Flow Planning}

\author{
Meegan Judd ${ }^{1 *}$, Nicholas Bond ${ }^{1}$ and Avril C. Horne ${ }^{2}$ \\ ${ }^{1}$ Centre for Freshwater Ecosystems, La Trobe University, Wodonga, VIC, Australia, ${ }^{2}$ School of Engineering, University of \\ Melbourne, Parkville, VIC, Australia
}

Implementing environmental flows has emerged as a major river management tool for addressing the impacts of hydrologic alteration in large river systems. The "natural flow paradigm" has been a central guiding principle for determining important ecohydrological relationships. Yet, climate change and associated changes in rainfall run off relationships, seasonality of flows, disruptions to food webs and species life cycle cues mean these existing relationships will, in many circumstances, become obsolete. Revised thinking around setting ecological objectives is required to ensure environmental management targets are achievable, particularly in regions where water scarcity is predicted to increase. Through this lens "climate ready" targets are those that are robust to changing water availability or incorporate future adaptation options. Future objective setting should be based around the inclusion of changing climate and water availability, and the associated species and ecosystem vulnerabilities, and expected outcomes under different policy and adaptation options. This paper uses south eastern Australia as a case study region to review the extent to which current water management plans include climate considerations and adaptation in objective setting. Results show untested climate adaptation inclusions, and a general lack of acknowledgement of changing hydrological and ecological conditions in existing management plans. In response this paper presents a process for setting objectives so they can be considered "climate ready."

Keywords: environmental flows, objectives, climate change, adaptation, water availability

\section{INTRODUCTION}

Increasing global populations and the demand for freshwater is resulting in water scarcity across many parts of the globe (Vörösmarty et al., 2000; Bond et al., 2019). Regulation of rivers for human water use has left many rivers with altered hydrology and degraded ecology (Bunn 2016), which will be further impacted by climate change (Smakhtin et al., 2004; Palmer et al., 2008; Vörösmarty et al., 2010). In many regions, water resources are being managed to maintain or reintroduce aspects of the natural flow regime in an effort to protect and improve the health of aquatic ecosystems by implementing environmental flows [elsewhere also referred to as environmental water (Horne A. et al., 2017; Arthington et al., 2018)]. Approaches to determining flow requirements for ecosystems are numerous, and reviews have outlined more than 200 recognised methods (Poff et al., 1997; Tharme 2003; Arthington et al., 2006; Nel et al., 2011). More recently, the challenges of assessing environmental flow requirements under a changing climate have been highlighted (Arthington et al., 2018). However, while there has been some discussion around the need for additional hydrological 
and ecological modelling to inform future environmental flow assessments (Tonkin et al., 2018; John et al., 2020), there has been little discussion of the likelihood of achieving the ecological targets that have historically been formulated in environmental flow planning. This paper addresses this gap by examining the requirement for "climate ready" targets, which we define as those identified as plausible and achievable under changing regimes of climate and water availability, and/or which incorporate vulnerability assessments and trade off options.

Clear objectives are considered an essential step in ecological stewardship, as they enable managers to determine appropriate management strategies, prioritise funds, track performance, and adaptively update management actions over time (Wilson and Law 2016). As water scarcity becomes more commonplace, setting realistic and attainable objectives at the commencement of any water recovery project becomes essential to achieving the ecological outcomes earmarked for water reallocation. Current environmental flow objectives focus on flow dependent environmental assets and particularly include species or communities, habitats and ecological processes (Acreman and Dunbar 2004; Yarnell et al., 2015). Objectives can be determined by legislative requirements, local community values, a panel of expert scientists or a combination of all of these (Cottingham et al., 2002; Horne A. C. et al., 2017).

Academic and grey literature outline many methods for setting objectives or goals in natural resource management (Tear et al., 2005; Edvardsson,2007; Gregory et al., 2012; Prober et al., 2018). For many decades the concept of "SMART" goal setting (Specific, Measurable, Attainable, Realistic, Time bound) (Doran 1981) has been widely accepted including in the fields of ecological restoration, and conservation and water management. The concept of SMART goals is still very relevant in the face of climate change, especially in setting goals or targets that are realistic and achievable in a non-stationary environment.

Currently, there are few examples of widely accepted SMART objective setting techniques being applied within environmental flows studies (Acreman and Dunbar 2004), with objectives often being poorly defined, deliberately vague (Wilson et al., 2009; Capon and Capon 2017), or untested as to their feasibility. Further, flow assessments are often required by government agencies to be undertaken within short time frames and with limited budgets, and consequently are not conducive to setting long-term objectives due to time constraints on gathering and processing new data (Arthington et al., 2006; Mezger et al., 2019).

Objective setting in environmental flow planning predominantly assumes the climate and environment is stationary with most goals defined based on some form of historic reference point - such as the restoration and/or rehabilitation of naturally abundant or endangered or iconic species and/or communities to a previous state (Dunlop et al., 2013; Hallett et al., 2013). Indeed most environmental flow methods are based on the assumption that ecosystem responses to flow regimes will remain the same in the future (Poff 2017; Horne et al., 2019; Tonkin et al., 2019). However, ecosystems are changing and recognition of this is needed in objective setting (Hobbs and Harris 2001; Choi 2007; Thompson et al., 2021). Further, there is currently little recognition of the impacts of climate change such as changing rainfall/runoff relationships and seasonality of flows and the impact of these on our ability to achieve existing objectives (the A and $\mathrm{R}$ in SMART). Increasing air and water temperatures will affect species physiology and ability to survive in situ, including growth rates and reproduction timing (Koehn et al., 2011; Bunn 2016). Bioclimatic envelope modelling suggests widespread geographic shifts and/or extinction of species due to water temperature changes and the exceedance of upper or lower thermal tolerance of species (Booth et al.,. 2011; Dawson et al., 2011; Comte and Olden 2017; Dudgeon 2019). Extreme events (droughts and floods) will become more frequent and will play an important role in shaping species populations, composition and diversity and as the frequency of these events increases, there will be limited ability of species to recover between events (Shenton et al., 2012; Harris et al., 2018). Reduced water availability and more frequent droughts will lead to an increased number of streams becoming ephemeral and consequent habitat fragmentation. Reduction in overbank and high spring flows will impact floodplain vegetation, life cycle cues for various species and hinder transport of carbon to the river impacting aquatic food webs (Morrongiello et al., 2011). Most of these climate change impacts are currently given little, or no, consideration when determining the objectives associated with environmental flows-both in terms of what the objectives should be, and whether they are feasible and/or robust to changes in water availability (Arthington et al., 2018).

It is now widely accepted that the climate is not stationary (Milly et al., 2008; Tonkin et al., 2019) and the current suite of environmental flow objectives aiming to restore conditions to an historic reference are unlikely to be achievable (Prober et al., 2012; Poff 2017; Capon et al., 2018; Thompson et al., 2021). This paper uses south eastern Australia as a case study to review the extent that current environmental water management plans include climate considerations and adaptation in objective setting. The results show that many current environmental flow objectives do not consider climate change, with untested climate adaptation inclusions, and a general lack of acknowledgement of changing hydrological and ecological conditions in existing management plans. Having identified this limitation with current plans, we examine the literature and identify four key challenges to achieving climate ready objectives for environmental flows (Section 4); 1. Environmental flow assessment methods rarely incorporate climate or water availability scenarios making it difficult to assess if their objectives are achievable in the long term. 2. High level of uncertainty around ecological responses to climate change and water scarcity including a lack of vulnerability assessments. 3. The spatial scale of ecological change and decision making does not align well with site specific environmental flow objectives. 4. Lack of guidance for objective setting to transition systems. We then present a process for setting future objectives so they can include such considerations (Section 5) to address the challenge of making environmental flow objectives "climate ready"; that is, being robust to changing water availability, or incorporating climate adaptation options. 


\section{WHAT DOES CLIMATE READY MEAN?}

Existing environmental flow objectives may result in maladaptive outcomes under climate change as hydrological and ecological responses alter from our historic knowledge base (Hansen and Hoffmam 2011; Capon and Capon 2017). Setting management objectives that are relevant under future climate scenarios has been recommended by Dunlop et al. (2013). "Climate ready" objectives, as referred to in this paper, are defined as objectives that include consideration of future changes in climate, flows and ecosystem response, and particularly include adaptations to these changes. Climate ready objectives link actions to future flow scenarios and ecosystem or species vulnerabilities and are informed by and provide benefit over a range of scenarios.

Several high level frameworks have been proposed for examining climate impacts. For example, the IPCC has widely used the Exposure, Sensitivity and Adaptive capacity framework (Sharma and Ravindranath 2019). However this framework has been criticised for not sufficiently distinguishing between sensitivity and adaptability in predicting ecosystem outcomes (Hinkel 2011; Fortini et al., 2013; Juhola and Kruse 2015). Fortini and Schubert (2017) presented a modified framework that integrates ecological knowledge in predicting how species and ecosystems may respond to changing climate conditions. Here we suggest ecosystem adaptation responses based on the work of Boltz et al. (2019) and Morrongiello et al. (2011);

- Persist/tolerate-the ability of an existing ecosystem or species to retain its function under changing conditions (Fortini and Schubert 2017). These are often generalist species.

- Can a species persist/remain in situ and within its thermal tolerance limit?

- Can a system return to the same ecological function after a recurring disturbance?

- Is there enough area and spatial distribution of habitat refuge?

- Are the tolerances to future scenarios known?

- Adaptability-enables the ecosystem to maintain its function regardless of the species it includes. Focusing water use on adaptation of ecological communities and processes rather than historic reference states or specific species will ensure objectives are achievable (Harris et al., 2006; Hansen and Hoffmam 2011; Prober and Dunlop 2011; Yarnell et al., 2015; Poff 2017; Capon et al., 2018).

- How connected are landscapes to facilitate migration to new habitats?

- Is vegetation complex enough to allow adaptation and resilience?

- Are carbon and energy cycles able to continue?

- Can genetic diversity be retained?

- Transformation/evolution-this will establish ecosystems with new functions in novel circumstances. Given the rapid pace of climate change and inability of species to rapidly evolve many ecosystems will transform to a new state (Fortini et al., 2013; Colloff et al., 2016).
- Are there obvious transformational pathways to a different community assembly?

- Is assisted migration or translocation necessary?

- Is it better to stock fish from hatcheries rather than promote spawning and recruitment in river/wetlands?

- Is there a need to conserve species outside of the natural environment?

Examples of objectives incorporating climate considerations that build on the three core species/ecosystem responses to climate change outlined above are proposed (Table 1). It is important to note that the suggested objectives address both ecosystem response to climate change (e.g., drought tolerant plants), and also management responses to climate change impacts (e.g. flexible objectives). Ideally, inclusion of climate considerations into objectives would include detailed hydrological modelling of future scenarios along with vulnerability assessments, however where this technical information is not available the objectives in Table $\mathbf{1}$ allow for input of general climate change adaptations based on the above three ecosystem responses. (Angeler et al., 2014; Foden et al., 2019; John et al., 2020).

\section{DO WATER PLANS IN SOUTH EAST AUSTRALIA HAVE CLIMATE READY OBJECTIVES?}

To determine the extent to which existing environmental flow plans for rivers in south east Australia consider climate impacts or adaptations, we evaluated a suite of documents against the recommended adaptation objectives (Table 1).

Throughout south east Australia climate change is already evident with average temperatures increasing between $0.6^{\circ} \mathrm{C}$ to just over $1^{\circ} \mathrm{C}$ since 1910 (Victorian Department of Environment 2019). Predicted future changes in temperature include a further increase in average, maximum and minimum temperatures of up to $0.7^{\circ} \mathrm{C}$ by 2040 and $2.4^{\circ} \mathrm{C}$ by 2070 (OEH 2014; Victorian Department of Environment 2019). Extreme hot days are also predicted to double by 2050, and winters will be warmer. Winter/ spring rainfall has already declined by around $12 \%$ since the late 1990 s, and warm season rainfall has increased. Future predictions suggest further rainfall reductions in spring by around 1\%-26\% by 2040 , and extreme rainfall events are likely to become more intense by the end of this century. Projected rainfall run off is expected to decrease by $5 \%-40 \%$ by 2050 , with three quarters of long term gauging stations in the Murray Darling Basin (MDB) already displaying a decline in flow since 1970 (BOM and CSIRO 2020; Department of Environment et al., 2020).

\subsection{The Region}

Inland south east Australia is dominated by the Murray Darling Basin (MDB), the most regulated river system in Australia. River regulation and water consumption in the MDB has resulted in overallocation of water for consumptive use and degraded riverine ecosystems (Ladson and Finlayson 2002; Grafton et al., 2014; Hart 2016; Horne A. et al., 2017). In 2007 the 
TABLE 1 | Example of ecological objectives that include consideration of climate impacts and adaptations.

Possible inclusions in future environmental water objectives

Justification or intent

Persistence

Maintain diversity of habitats; including refuges $\quad$ 1. Maintain key ecosystem features e.g., buffer zones, structural complexity of vegetation, diversity of geomorphic features, protection of water quality

2. Consider drought induced low flows or provision or maintenance of refuges (pool habitat for low flow/drought conditions)

3. Seek to maintain dynamic ecological outcomes rather than restore to an historic state (e.g., uses maintain rather than restore/protect)
Many of these aspects are also relevant to adaptation, yet the ability to persist relies on "protection" of these features in the landscape West et al. (2009)

Allows species to persist in situ during periods of drought West et al. (2009)

Aims to maintain attributes of current ecosystems that could persist rather than aim for an historic reference point Dunlop et al. (2013)

\section{Adaptation}

Maintain habitat and ecological function; focus on population diversity and dynamics, carbon cycling
4. Consider and provide for habitat diversity, connectivity and/or conservation

Encourage increased movement of species from one ecosystem to another (e.g., to new habitats within an acceptable thermal tolerance range)

5. Maintain a diversity of species, without mention of specific species

6. Ensure carbon cycling and energy sources for aquatic and riparian productivity are maintained

7. Aim for high functional redundancy and diversity within an ecosystem
Increased habitat diversity and connectivity improves resilience by enabling species to migrate to new locations with more tolerable climate and thermal tolerance zones, or adapt to changing conditions Comte and Olden. (2017); Fortini et al. (2013); Palmer et al.(2009)

Aiming for species diversity, rather than species specific conservation, the ecosystem can include species with similar functions rather than focusing on protection of endangered or highly vulnerable species

Allows for continuation of some ecosystem function regardless of species/communities Lin and Petersen. (2013)

Encouraging large functional groups whereby one species can fill the void made by another species of similar function if extinction occurs

\section{Transformation}

Actively promote change

8. Objectives that are flexible, and achievable, with changing water availability (e.g., they are achievable under flood and long term drought conditions)

9. Allow the establishment of locally non native species that preserve regional biodiversity or sustain ecological functions

10. Consider ex situ conservation or active translocation of species to a new site
Objectives need to be flexible to changing water availability and updated as climate and river flow scenarios become available

Allows for potentially more suitable, climatically tolerant species to fill a gap after disturbances, and provides for the greatest diversity possible (e.g. stocking fish) West et al. (2009)

Species vulnerability assessments coupled with climate scenarios will reduce uncertainty around viability of species in certain locations. Incorporating this information into environmental flow assessments will help with trade off decisions regarding translocation and triage
Federal government passed the Water Act 2007 which required the development of a strategic plan for river health (the Basin Plan) and set volumetric limits on how much water can be used for consumptive use and how much should be used to maintain ecological condition. The Water Act 2007 enables the Australian Government to recover water for the environment in several ways (water buy backs, irrigation infrastructure upgrades) and provides ecological objectives for the use of the recovered water. Other parts of south east Australia included in this case study are those in southern Victoria, including rivers around Melbourne and river systems that end in estuary's or coastal lakes (e.g., Glenelg River, LaTrobe River).

\subsection{Method}

We reviewed a total of 422 riverine environmental flow objectives from 44 separate documents describing flow requirements for rivers in Victoria, southern New South Wales (NSW) and the Murray River in South Australia (SA). The objectives were assessed against the climate adaptation objectives outlined in Table $\mathbf{1 .}$

Documents reviewed were public documents obtained directly from the organisation or indirectly via the organisation's website. The documents analysed were environmental flow studies, annual watering plans or longer term (10 years) environmental water management plans from local, state and federal government agencies (e.g., Catchment Management Authorities, state governments, water holders, the Commonwealth Basin Plan). The longest time frame for the development of environmental flow objectives was associated with the draft NSW Long Term Water Plans, which set objectives outlining environmental outcomes and 5, 10 and 20 years targets for each objective, and a review of the plan every 5 years to evaluate the targets. The date range of the plans 
TABLE 2 | Assessment results comparing existing environmental flow planning documents against the climate change adaptation objectives of Table 1 (See Supplementary Material for more detail).

Example objectives that incorporate climate change adaptations (from Table 1)

\begin{tabular}{|c|c|c|}
\hline $\begin{array}{l}\text { Number of } \\
\text { objectives }\end{array}$ & $\begin{array}{l}\text { Number of } \\
\text { objectives }\end{array}$ & $\begin{array}{l}\text { Percent of } \\
\text { objectives }\end{array}$ \\
\hline $\begin{array}{l}\text { that meet this } \\
\text { criterion }\end{array}$ & $\begin{array}{l}\text { that could } \\
\text { meet } \\
\text { this criterion }\end{array}$ & $\begin{array}{l}\text { that could } \\
\text { meet } \\
\text { this criterion }\end{array}$ \\
\hline
\end{tabular}

\begin{tabular}{|c|c|c|c|c|}
\hline \multicolumn{5}{|c|}{ Persistence-Aims to maintain habitats and features, including refuges } \\
\hline 1 & $\begin{array}{l}\text { Maintain key ecosystem features that can support and } \\
\text { underpin the overall system e.g. buffer zones, riparian } \\
\text { areas incorporating drought tolerant plants, structural } \\
\text { complexity of vegetation, protect nursery and spawning } \\
\text { areas West et al. (2009) }\end{array}$ & 158 & 183 & $86 \%(n=183)$ \\
\hline 2 & $\begin{array}{l}\text { Considers drought induced low flows or provision or } \\
\text { maintenance of refuge or pool habitat for low flow/drought } \\
\text { conditions }\end{array}$ & 11 & 33 & $33 \%(n=33)$ \\
\hline 3 & $\begin{array}{l}\text { Seek to maintain ecological outcomes rather than restore } \\
\text { to an historic state (e.g. uses maintain rather than restore/ } \\
\text { protect) }\end{array}$ & 182 & 230 & $79 \%(n=230)$ \\
\hline
\end{tabular}

Adaptation - Provides for improved migration and maintenance of ecological function

\begin{tabular}{|c|c|c|c|c|}
\hline 4 & $\begin{array}{l}\text { Considers habitat diversity, connectivity and/or } \\
\text { conservation }\end{array}$ & 98 & 155 & $63 \%(n=155)$ \\
\hline 4 & $\begin{array}{l}\text { Encourages increased movement of species (e.g. to new } \\
\text { habitats within an acceptable thermal tolerance range) }\end{array}$ & 48 & 83 & $58 \%(n=83)$ \\
\hline 5 & $\begin{array}{l}\text { Aim to maintain a diversity of species, without mention of } \\
\text { specific species }\end{array}$ & 84 & 122 & $69 \%(n=122)$ \\
\hline 6 & $\begin{array}{l}\text { Ensure carbon cycling and energy sources for aquatic and } \\
\text { riparian productivity are maintained }\end{array}$ & 18 & 22 & $81 \%(n=22)$ \\
\hline 7 & $\begin{array}{l}\text { Aim for high functional redundancy and diversity within an } \\
\text { ecosystem }\end{array}$ & 19 & 41 & $46 \%(n=41)$ \\
\hline
\end{tabular}

Transformation-Objectives that actively promote change and/or are flexible to change

\begin{tabular}{|c|c|c|c|c|}
\hline 8 & $\begin{array}{l}\text { Objectives that are flexible, and achievable, with changing } \\
\text { water availability }\end{array}$ & 8 & 15 & $60 \%(n=15)$ \\
\hline 9 & $\begin{array}{l}\text { Allow the establishment of locally non native species that } \\
\text { maintain native biodiversity or ecosystem function in the } \\
\text { overall region West et al. (2009) }\end{array}$ & 13 & 22 & $59 \%(n=22)$ \\
\hline 10 & $\begin{array}{l}\text { If there was any suggestion for ex situ conservation or } \\
\text { active translocation }\end{array}$ & 0 & 1 & $0 \%(n=1)$ \\
\hline
\end{tabular}

assessed was from 2010 to 2020 , a date range we considered adequate to anticipate potential inclusion of climate change impacts. A list of documents assessed are provided in the Supplementary Material.

The analysis focused on specific documented objectives, and ignored visions and goals, which in most reports simply mirrored higher level policy goals and were generally too vague to evaluate against our specific criteria. Duplicate objectives stated in more than one document for the same system were identified and ignored to avoid double counting. This case study is chiefly focused on the southern MDB, but also includes objectives from southern Victorian catchments. Of the documents assessed, $60 \%$ were from the southern MDB and $40 \%$ were from southern Victoria. Not all climate adaptation objectives (Table 1) were relevant to all the existing objectives assessed e.g., where an existing objective was focused on physical habitat, the adaptation objective relevant to species diversity is not applicable.

\subsection{Results}

When assessing existing objectives against our adaptation objectives, the existing objectives most frequently relied on persistence and adaptation strategies (Table 2 and Figure 1).

Within the persistence response category, the recommendation most frequently met was that aimed at maintaining ecological outcomes rather than restoring them (3). Under this adaptation objective, many of the existing objectives aim to maintain populations of specific species, including threatened species, or maintain components of the environment to be in similar condition to a previous or current state. Further, based on a word search of the objectives, there has been a relative decline in the use of the words "restore" and "protect," and an increase in the use of "maintain" suggesting a general recognition that restoring populations may no longer be possible. This is an important recognition by water managers however there is no specific mention in existing objectives that connects this change of focus to consideration of future climate or 


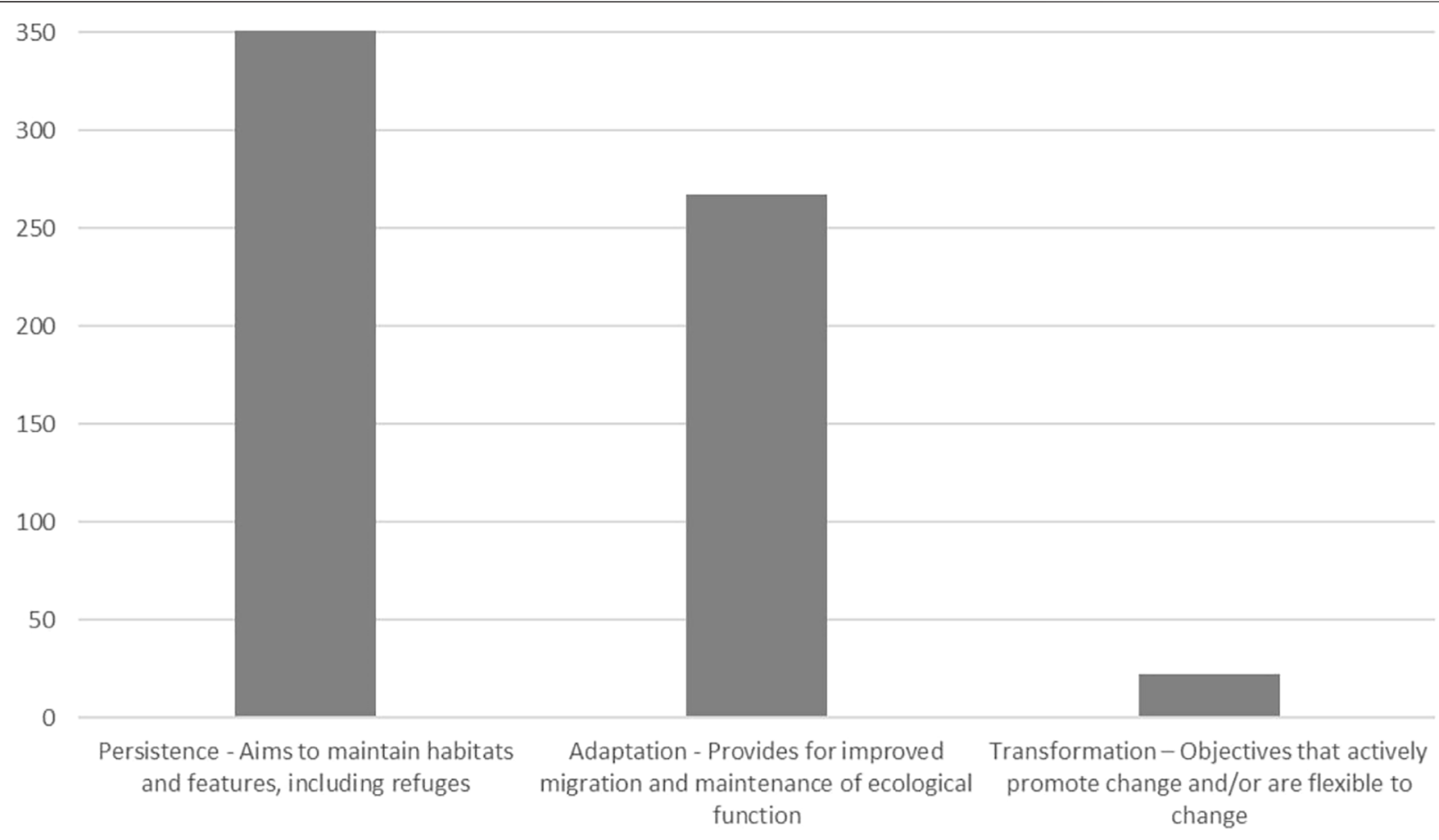

FIGURE 1 | Number of existing flow objectives that meet the suggested climate change adaptation objectives.

water availability, or if it is due to other considerations. The Murray Darling Basin Plan (2012), and NSW long term water plans (which link closely with the Basin Plan), include numerous objectives with the wording "protect and restore", "increase the distribution and abundance" of fish, vegetation and waterbirds. It has been widely documented that the Basin Plan does not adequately address climate change (Young et al., 2011; Pittock et al., 2015; Alexandra 2017) and this is evidenced by the objectives assessed here. In the documents assessed for this case study there were seven occurrences of objectives from the Basin Plan stating "protect and restore" compared with two occurrences of this wording in non Basin Plan documents.

From the adaptation response category, the two objectives met most often were those considering habitat diversity, conservation and connectivity (4), and those aiming to maintain a diversity of species (5); both categorised as adaptation response. The high frequency of objectives addressing habitat diversity, conservation and connectivity (4) is a good start, however these objectives are very broad. Examples of objectives in this category include maintaining flow connectivity, improving vegetation zonation, and maintaining inset benches and other geomorphologic features. Although all these issues contribute to habitat connectivity or diversity this category is now considered too general and does not extract specific habitat function objectives. For future use this response category would be best separated into habitat function, habitat connectivity and habitat availability.

Very few objectives specifically mention climate change or its impacts. A search for the words "climate change" show it is mentioned just five times from the 422 objectives assessed. Overall, existing objectives provide some climate change adaptations as defined by response categories of Section 2, however this is commonly a result of generic wording rather than an explicit recognition of ecohydraulic relationship changes under climate change.

Of the objectives assessed, very few included proactive consideration of climate change adaptation (objectives that meet the transformation response). While most existing planning documents include some kind of adaptation response, many of the objectives did not specifically refer to climate change e.g., Provide periodic opportunities for regeneration of riparian, floodplain and wetland plant species falls into the "maintain a diversity of species" adaptation category without recognition that floodplain and wetland watering will become more difficult under climate change. Without inclusion of vulnerability assessments and detailed hydrologic modelling that takes future flows into account, these type of objectives are unlikely to be feasible. None of the documents assessed in this case study included detailed hydrologic modelling of future flow and/or vulnerability assessments, and therefore had no evidence to support the "achievability" of these objectives in a changed future.

There were few objectives in the transformation response group, such as encouraging the establishment of non locally native species to maintain ecosystem function, and there were zero objectives that considered active translocation of species to more suitable habitats. Translocation is more likely to be required for threatened or specialist species rather than for generalists or species able to disperse on their own. Transformation may seem radical and costly, but if not considered, current environmental water management may lead to maladaptation and increased 
environmental loss. Thoughtful decisions around transformation should be a well considered proactive response to an uncertain future. Further, if transformation actions are undertaken, it may alter objectives for environmental water use in a river system and can provide opportunities for co-design of visions and management strategies by riverine communities.

The remainder of this paper discusses the challenges of preparing the environmental water industry to develop climate ready ecological objectives and finally, we propose a process to enable this to happen.

\section{WHAT ARE THE MAJOR CHALLENGES FOR INCORPORATING CLIMATE CHANGE?}

There have been high level discussions on the need to consider climate change in environmental flow objectives, yet the lack of guidance on how to implement this is hindering inclusion (Kiem et al., 2016; Poff 2017). Most existing methods for determining objectives do not sufficiently address the challenges of an uncertain, non stationary future in terms of altered hydrology and ecology. There is significant literature relating objective setting to SMART guidelines, yet environmental flow objective setting fails in the transparency required from a SMART objective setting methodology. When considering non stationarity, this limitation will become more pertinent as objective setting will require clear articulation of what is valued and desired, and how realistic this will be. Specific challenges that need to be considered to move the practice forward include: (1) Environmental flow assessment methods rarely incorporate climate scenarios or water availability outlooks (Shenton et al., 2012; Horne et al., 2019) making it hard to assess if their objectives are "Attainable" and "Realistic." (2) High level of uncertainty around ecological responses to climate change and water scarcity including a lack of species vulnerability assessments (3) The spatial scale of ecological change and decision making does not align well with site specific environmental flow objectives (4) Lack of guidance for objective setting to transition systems. Each of these issues in discussed in more detail below.

\section{Water availability under climate scenarios}

Current environmental flow assessments typically look at historic water availability with little consideration for long term future water availability or change. A challenge to include long term future water availability lies in the large knowledge gaps of climate change forecasting including how the climate will respond to future greenhouse emission levels, and the sequencing in global climate models of extreme events (Hallegatte et al., 2012). There is also much debate around downscaling methods, and the data and resources required to derive regionally relevant information.

There are also many knowledge gaps on the effect on local rainfall/run off (Saft et al., 2016), seasonality of flows, and water quality (Arora et al., 2017). It is perhaps these large uncertainties that has limited the incorporation of future scenarios and run off changes into objective setting. While scenarios have been used within decision making and environmental flow assessments (King et al.,. 2000; King and Brown 2010), they rarely link back to an assessment of the objectives under the SMART framework (particularly the Attainable and Realistic).

One potential approach to address this uncertainty in future outcomes and link back to the achievability of objectives is to include fit for purpose and commonly agreed hydrologic models using a range of stochastic data and narrative scenarios within environmental flow assessment methods (Horne et al., in prep, John et al., in prep). To demonstrate the potential ramifications of incorporating water availability scenarios, a recent study in the Goulburn River, Victoria (Australia) identified floodplain vegetation condition as a high priority objective and resulted in a recommendation for overbank flows. However, with the inclusion of climate change it was found that overbank flows would likely decrease by $12 \%-36 \%$ under a moderate to high climate impact scenario, making this objective challenging to achieve without significant reoperation of the river (Horne et al., in prep). Using climate/rainfall runoff scenarios to inform decision making and objective setting should be included in future flow assessments.

\section{Uncertainty of ecosystem response to climate change}

There are many uncertainties around how species, communities and ecosystems will respond to hydrological change and their vulnerability to climate change which may be restricting the ability of water managers to develop climate ready objectives (Kiem et al.,. 2016; Tonkin et al., 2018). Poff (2017) suggests future environmental flow management needs to include ecological vulnerability assessments (EVAs). EVAs examine the pressures climate change will have on a particular species or taxonomic group and assesses their sensitivity (the degree that a system is affected (adversely or beneficially) by climate change), exposure (nature, magnitude and rate of change to a species) and capacity to adapt (ability of a species or ecosystem to adjust to climate change and/or benefit from opportunities or to respond to the effects) (De Lange et al., 2010; Mastrandrea et al., 2010; Pielke Sr et al., 2012; Foden and Young 2016).

Vulnerability assessments can be undertaken at the species or ecosystem level, investigating different types of impact (e.g., decline in diversity or ecosystem function, to species extinction), at a range of spatial and temporal scales and can consider various climate change impacts such as direct climate response, to predicted land use change in response to climate impacts.

The three main methods for vulnerability assessments are:

1. Correlative approach - uses models to determine the correlation between a species distribution range and its historical climate requirements. This information is subsequently combined with future climate projections to predict areas of suitable climate for future distribution. These models are sometimes called niche-based or species distribution models.

2. Traits based approach - uses species biological characteristics to estimate their sensitivity and capacity to adapt to estimates 
of their exposure to climate change. The scores for sensitivity, adaptive capacity and exposure are then combined to determine the vulnerability of a species.

3. Mechanistic approaches - uses process based models and incorporates biological processes, thresholds and interactions to predict a species response to changing environmental conditions. These models can incorporate species longevity and fecundity, predation and competition, and changes in habitat suitability in response to climate change, along with land use change (Foden and Young 2016).

There are pros and cons of each of these three methods and while interest in applying vulnerability assessments has increased in the last ten or so years (Foden et al., 2019), the method adopted will depend on available data and resources. Fortini et al. (2013) developed and tested a method to assess plant species vulnerability to climate change which could be adapted to other ecosystems. They focused on species responses to changes in habitat-specifically area, quality and distribution - under a changing climate. Four species responses included in the vulnerability assessment include tolerate, remain in microrefugia, migrate and evolutionary adaptation. These responses are commonly referred to as methods of adaptation in adaptation literature.

Although there are limitations and uncertainties involved with vulnerability assessments, the inclusion of species vulnerability assessments in future flows assessments would provide water managers with improved information to develop more robust objectives. Vulnerability assessments will increase the knowledge available to water managers on whether species are likely to persist or adapt in the environment, or if a focus on transformation is required. Upscaling species vulnerability assessments to a guild or community level could then be translated to broader spatial scales. Combining climate/rainfall runoff scenarios and species vulnerability assessments would greatly reduce uncertainty for future flow assessments.

\section{Spatial scale}

Many flow assessments are conducted at the scale of individual river systems, and in some cases at even finer scales. However, life cycle requirements of flora and fauna require interconnectedness of flow regimes. Continuing to develop objectives restricted to a single river scale will not enable long term trade off evaluations to be made. Larger spatial scale planning will enable different river systems to be prioritised for certain life stages of species and habitat connectivity and linkage corridors between fragmented habitats (Hobbs and Norton 1996; Stein et al., 2013). Regional, or basin, spatial scale management, rather than local, will become a necessity to maintain ecosystem function, and increasingly important as water availability decreases and reduces the ability to target the same objective at multiple sites (Heller and Zavaleta 2009).

4. Acceptance to proactively manage intervention (transition the ecosystem)

One adaptation action that needs to be addressed in environmental flow assessments, but which is currently largely ignored is the option to actively manage the river system to a new state (West et al., 2009; Colloff et al., 2016; Thompson et al., 2021). This includes consideration of management actions such as translocation of species to new habitats, relying on stocking of species rather than self-sustaining populations, and conservation triage. This type of adaptation action recognises that under climate change, water resources will not be able to conserve all species at all locations and that environmental water can be used as a tool for ecological transformation rather than restoration. Proactively managing intervention ensures ecosystem functions are retained and aims to avoid system collapse (Lin and Petersen 2013). Although these types of actions may not be required in the immediate future and existing objectives may in fact be suitable in the long term, if consideration of proactive adaptation is not adopted future reactive adaptation is likely to be more costly to the environment, society and economically, with potentially higher losses to rivers, wetlands and local communities (Boltz et al., 2019).

\section{A PROCESS TO DEVELOP CLIMATE READY ENVIRONMENTAL FLOW OBJECTIVES}

We propose a new process to develop "climate ready" objectives that considers non-stationarity and attempts to address the four challenges discussed above (Figure 2). Under our proposed process, objective setting should be iterative, where objectives are informed by scientists to reflect both the values and desires of the community and meet the requirements of any legislation. Community involvement is important for gaining legitimacy for environmental flows and ensuring local communities, including indigenous communities, are given a voice in the decision making process (Pahl-Wostl et al., 2013; Anderson et al., 2019). This will be increasingly important where objectives move towards adaptation and transformation, rather than maintaining or restoring existing condition.

Initial objectives, which can be based around ecosystem response adaptations as per Table $\mathbf{1}$ or developed independently, are tested against climate change scenarios, sequences of possible extreme events, predicted water use and vulnerability assessments to determine if the objectives are achievable in the long term. This is a crucial new step and addresses the challenges outlined in Section 4. Due to the large uncertainty and constantly updated information around climate and associated ecological changes, setting objectives without the inclusion of the most up to date technical information may lead to unachievable and irrelevant objectives. While there are challenges of combining hydrology, ecology and climate science (John et al., 2020), there is a need to proactively manage riverine environments to enhance resilience and future transformation.

If the objectives cannot be met under possible futures, a trade off decision is required. The trade off decision will need to determine what measures will be acceptable (for community, government and the environment) to continue pursuing the desired objective, or when a revision of objectives is best. This 


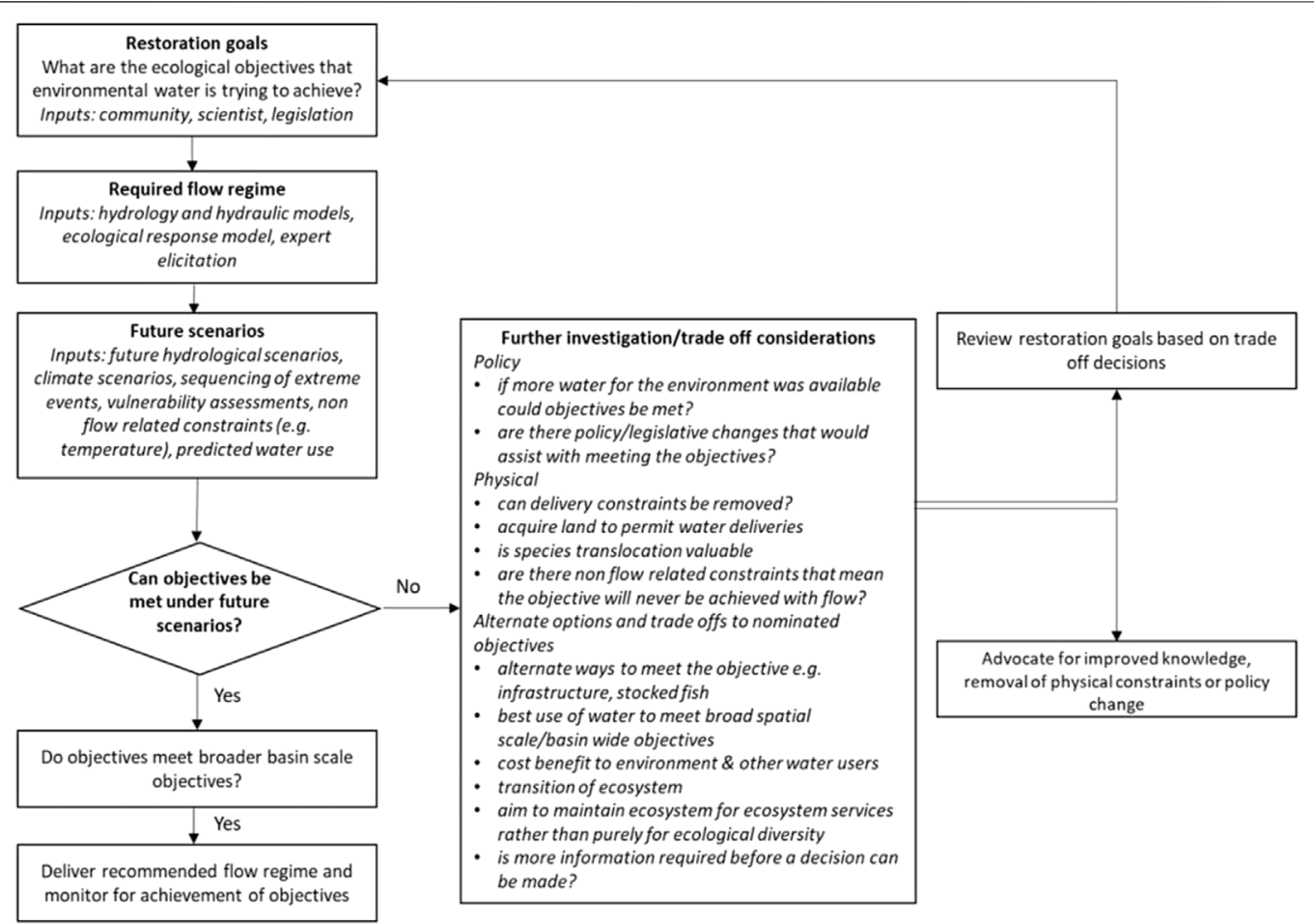

FIGURE 2 | Process to establish climate ready objectives in future flow assessements.

TABLE 3 | Examples of trade off considerations required in setting future environmental flow objectives.

\section{Trade off considerations}

Are there alternate ways to achieve the objectives?

Where is the best use of environmental flows on a basin wide scale?

Cost benefit to achieving the environmental objective

Cost benefit to other water users

Sequencing of extreme events such as drought

Willingness of the community to transition to a new state

Revise objectives for the region

\section{Example}

If the objective is to provide abundant recreational fish populations, can these be stocked fish rather than naturally spawned and recruited?

If the river and each tributary is delivering a flow component to achieve the same objective, can the same result be achieved by delivering water to just a limited number of rivers e.g. is fish spawning required in every tributary of a basin?

Decisions need to be made for retaining a representative area of each ecosystem rather than trying to maintain all areas where water scarcity increases

If the objective of delivering overbank flows requires levee construction or land acquisition on the floodplain, is the ecological benefit greater than economic and social cost?

To achieve a desired environmental flow objective larger volumes of water may be required to be re-allocated from agricultural or other consumptive use. Are existing irrigation areas sustainable in the long term? Can urban communities recycle more water?

Developing objectives for 2-5 consecutive dry years and/or 5-10 consecutive dry years will provide information on life cycle thresholds of species and allow decisions to be made on how long to provide water during periods of drought

Where future conditions will not sustain the historical complement of species could an alternative suite of species deliver the same goods and/or services or ecological function, be acceptable to the community? Does the community invest money in maintaining the full suite of current species, including endangered species, or trade off some species to save others?

Are the objectives for restoration goals sustainable in the long term, or should objectives be aimed at ecosystem services? 
decision can be informed by climate adaptations such as: spatial considerations, the best use of future water and its availability, and ecosystem function and potential requirements to actively transition the ecosystem to new state. However, in making these trade off decisions each system will have different legacy issues and community values, resulting in potentially different decisions. This would be a new step in most environmental flows assessments and leads to a clear articulation of the decision making process when finalising objectives. Thompson et al. (2021) have developed a management decision framework where managers can "resist, accept or direct" actions in response to climate change. This could be combined with our proposed process to implement "climate ready" actions developed in Figure 2.

With increased water scarcity under climate change, trade off decisions in environmental flow management will become standard practice in environmental flows assessments. Issues and examples that will need to be considered in trade off decisions will be many and complex (Table 3). Trade off decisions will not only need to consider ecological outcomes, but also the economic and social impact on other water users, land use and planning, along with recreational and aesthetic values held by impacted communities. A thorough participatory education, consultation and negotiation process will enable trade offs and development of future objectives that will be achievable and accepted by river managers and communities.

Once trade off decisions are made, environmental flow objectives may need to be revised. When revising objectives, adaptation actions should be incorporated and focus on managing for diversity of functional groups, improving migration and reducing barriers to movement through the landscape, increasing the resilience of the system to cope with change, or actively promote change to a novel state (Table 1). It is only by going through this process in its entirety that objectives will be truly "climate ready."

Incorporating these additional tasks for implementing climate ready objectives will initially significantly increase the complexity, time and resources required for determining environmental flow requirements, yet without doing so, water managers cannot make informed, proactive decisions and trade offs when managing riverine environments into the future. All objectives should be supported by the best available science (Horne A. et al., 2017), monitoring data and should be updated regularly. The framework should be re-evaluated at short, regular time frames (e.g., 5 years) as new climate/water, and species information, along with monitoring data become available. Without including these considerations in objective setting, environmental flows are unlikely to be able to achieve the stated objectives, may lead to maladaptation and lose support from local riverine communities. However, where resources to implement the recommended framework are not available or where appropriate climate and hydrology scenarios, and species data are scarce, managers should consider incorporating adaptation and transformation objectives as a minimum (Table 1).

\section{CONCLUSION}

There is a need to establish clear best practice guidelines for managers, scientist and consultants involved in developing environmental flow goals under a changing climate. It is clear from this research and thorough reading of current environmental flow plans from south east Australia that current environmental flow assessment do not include climate ready flow objectives, do not adequately include future climate and flow scenarios, and none have incorporated species or ecosystem vulnerability assessments. Most objectives assessed in the case study referred to current or historic states considered achievable in a stationary environment where relationships of the past will carry through to the future. However, under climate change objectives need to incorporate adaptations to new hydrological and ecological conditions by increasing ecosystem resilience and the ability to transform.

There remain critical knowledge gaps that are limiting the ability to adapt environmental water management to a non stationary future (Capon et al., 2018). An encouraging start to closing the knowledge gap is the monitoring of environmental water outcomes and adaptive management that is currently occurring in south east Australia (Watts et al., 2020). However, the lack of future hydrologic modelling and vulnerability assessments that can help determine the ability of a species or ecosystem to withstand, or how it may change, in response to a changing climate and more frequent extreme events is greatly lacking. By incorporating the latest monitoring and adaptive management results and available climate, flow and vulnerability scenarios, water managers will be better equipped to set objectives that are SMART and climate ready. Once this information is available more informed and transparent trade off decisions can be made and truly 'climate ready' objectives can be set. Trade off decisions will need to incorporate ecological information but also be negotiated with all impacted water and river users to ensure legitimacy of environmental water use, and full consideration of social and economic implications. The need to make trade off decisions and negotiations will only increase as competition for water and its availability shifts under climate change.

Equipping water managers with the most up to date tools and information to proactively manage water sustainability into an uncertain future is vital to achieve desired ecological outcomes. The process proposed in this paper should be applied to catchment and basin wide environmental flow decisions and updated as new information becomes available. If this or a similar process is not adopted, future objectives will be inadequate in preparing and/or supporting river managers in achieving policy objectives.

\section{DATA AVAILABILITY STATEMENT}

The raw data supporting the conclusion of this article will be made available by the authors, without undue reservation. 


\section{AUTHOR CONTRIBUTIONS}

MJ performed the analysis and prepared the draft manuscript. $\mathrm{AH}, \mathrm{NB}$ and $\mathrm{MJ}$ contributed to manuscript revision, read, and approved the submitted version.

\section{FUNDING}

$\mathrm{MJ}$ is funded through an industry $\mathrm{PhD}$ scholarship with funding from the Department of Environment, Land,

\section{REFERENCES}

Acreman, M. C., and Dunbar, M. J. (2004). Defining Environmental River Flow Requirements - a Review. Hydrol. Earth Syst. Sci. 8 (5), 861-876. doi:10.5194/ hess-8-861-2004

Alexandra, J. (2017). Risks, Uncertainty and Climate Confusion in the MurrayDarling Basin Reforms. Water Econs. Pol. 03 (03), 1650038. doi:10.1142/ s2382624x16500387

Anderson, E. P., Jackson, S., Tharme, R. E., Douglas, M., Flotemersch, J. E., Zwarteveen, M., et al. (2019). Understanding Rivers and Their Social Relations: A Critical Step to advance Environmental Water Management. WIREs Water 6 (6), e1381. doi:10.1002/wat2.1381

Angeler, D. G., Allen, C. R., Birgé, H. E., Drakare, S., McKie, B. G., and Johnson, R. K. (2014). Assessing and Managing Freshwater Ecosystems Vulnerable to Environmental Change. Ambio 43 (1), 113-125. doi:10.1007/s13280-0140566-z

Arora, M., Casas-Mulet, R., Costelloe, J. F., Peterson, T. J., McCluskey, A. H., and Stewardson, M. J. (2017). "Impacts of Hydrological Alterations on Water Quality," in Water for the Environment (Amsterdam: Elsevier), 101-126. doi:10.1016/b978-0-12-803907-6.00006-1

Arthington, A. H., Bhaduri, A., Bunn, S. E., Jackson, S. E., Tharme, R. E., Tickner, D., et al. (2018). The Brisbane Declaration and Global Action Agenda on Environmental Flows (2018). Front. Environ. Sci. 6, 45. doi:10.3389/fenvs.2018. 00045

Arthington, A. H., Bunn, S. E., Poff, N. L., and Naiman, R. J. (2006). The challenge of Providing Environmental Flow Rules to Sustain River Ecosystems. Ecol. Appl. 16 (4), 1311-1318. doi:10.1890/1051-0761(2006)016[1311:tcopef]2.0.co;2

Boltz, F., LeRoy Poff, N., Folke, C., Kete, N., Brown, C. M., St. George Freeman, S., et al. (2019). Water Is a Master Variable: Solving for Resilience in the Modern Era. Water Security 8, 100048. doi:10.1016/j.wasec.2019.100048

BOM; CSIRO (2020). State of the Climate 2020. Melbourne: Bureau of Meteorology; Commonwealth Scientific and Industrial Research Organisation.

Bond, N. R., Burrows, R. M., Kennard, M. J., and Bunn, S. E. (2019). "Water Scarcity as a Driver of Multiple Stressor Effects," in Multiple Stressors in River Ecosystems. Editors S Sabater, A Elosegi, and R Ludwig (Amsterdam: Elsevier), 111-129. doi:10.1016/b978-0-12-811713-2.00006-6

Booth, D. J., Bond, N., and Macreadie, P. (2011). Detecting Range Shifts Among Australian Fishes in Response to Climate Change. Mar. Freshw. Res. 62 (9), 1027-1042. doi:10.1071/mf10270

Bunn, S. E. (2016). Grand challenge for the Future of Freshwater Ecosystems. Front. Environ. Sci. 4, 21. doi:10.3389/fenvs.2016.00021

Capon, S., Leigh, C., Hadwen, W., George, A., McMahon, J., Linke, S., et al. (2018). Transforming Environmental Water Management to Adapt to a Changing Climate. Front. Environ. Sci. 6, 80. doi:10.3389/fenvs.2018.00080

Capon, S. J., and Capon, T. R. (2017). An Impossible Prescription: Why Science Cannot Determine Environmental Water Requirements for a Healthy MurrayDarling Basin. Water Econs. Pol. 03 (03), 1650037. doi:10.1142/ s2382624x16500375

Choi, Y. D. (2007). Restoration Ecology to the Future: A Call for New Paradigm. Restor Ecol. 15 (2), 351-353. doi:10.1111/j.1526-100X.2007.00224.x

Colloff, M. J., Doherty, M. D., Lavorel, S., Dunlop, M., Wise, R. M., and Prober, S. M. (2016). Adaptation Services and Pathways for the Management of
Water and Planning, Victoria, Australia and Goulburn Broken Catchment Management Authority, Victoria, Australia. AH was funded through an ARC DECRA award (DE180100550).

\section{SUPPLEMENTARY MATERIAL}

The Supplementary Material for this article can be found online at: https://www.frontiersin.org/articles/10.3389/fenvs.2022.714877/ full\#supplementary-material

Temperate Montane Forests under Transformational Climate Change. Climatic Change 138 (1-2), 267-282. doi:10.1007/s10584-016-1724-z

Comte, L., and Olden, J. D. (2017). Climatic Vulnerability of the World's Freshwater and marine Fishes. Nat. Clim Change 7 (10), 718-722. doi:10. 1038/nclimate3382

Cottingham, P., Thoms, M. C., and Quinn, G. P. (2002). Scientific Panels and Their Use in Environmental Flow Assessment in Australia. Australas. J. Water Resour. 5 (1), 103-111. doi:10.1080/13241583.2002.11465196

Dawson, T. P., Jackson, S. T., House, J. I., Prentice, I. C., and Mace, G. M. (2011). Beyond Predictions: Biodiversity Conservation in a Changing Climate. Science 332 (6025), 53-58. doi:10.1126/science.1200303

De Lange, H. J., Sala, S., Vighi, M., and Faber, J. H. (2010). Ecological Vulnerability in Risk Assessment - A Review and Perspectives. Sci. Total Environ. 408 (18), 3871-3879. doi:10.1016/j.scitotenv.2009.11.009

Department of Environment (2020). "Water and Planning; Meteorology; Bo, Organisation; CSaIR \& Melbourne, TUo," in Victoria's Water in a Changing Climate (Melbourne: Department of Environment, L).

Doran, G. T. (1981). There's a SMART Way to Write Management's Goals and Objectives. Management Rev. (AMA Forum) 70 (11), 35-36.

Dudgeon, D. (2019). Multiple Threats Imperil Freshwater Biodiversity in the Anthropocene. Curr. Biol. 29 (19), R960-R967. doi:10.1016/j.cub.2019.08.002

Dunlop, M., Parris, H., and Ryan, P. (2013). Climate-ready Conservation Objectives: A Scoping Study. QLD, Australia: National Climate Change Adaptation Research Facility.

Edvardsson, K. (2007). Setting Rational Environmental Goals: Five Swedish Environmental Quality Objectives. J. Environ. Plann. Manag. 50 (2), 297-316. doi:10.1080/09640560601156540

Foden, W. B., Young, B. E., Akçakaya, H. R., Garcia, R. A., Hoffmann, A. A., Stein, B. A., et al. (2019). Climate Change Vulnerability Assessment of Species. Wiley Interdiscip. Rev. Clim. Change 10 (1), e551. doi:10.1002/wcc.551

Foden, W. B., and Young, B. E. (2016). IUCN SSC Guidelines for Assessing Species' Vulnerability to Climate Change. Switzerland: IUCN Cambridge, England and Gland.

Fortini, L. B., Price, J., Jacobi, J., Vorsino, A., Burgett, J., Brinck, K. W., et al. 2013, A Landscape-Based Assessment of Climate Change Vulnerability for All Native Hawaiian Plants, No. University of Hawaii, Technical Report HCSU-044.

Fortini, L., and Schubert, O. (2017). Beyond Exposure, Sensitivity and Adaptive Capacity: a Response Based Ecological Framework to Assess Species Climate Change Vulnerability. Clim. Chang Responses 4 (1), 2. doi:10.1186/s40665-0170030-y

Grafton, R. Q., Pittock, J., Williams, J., Jiang, Q., Possingham, H., and Quiggin, J. (2014). Water Planning and Hydro-Climatic Change in the Murray-Darling Basin, Australia. Ambio 43 (8), 1082-1092. doi:10.1007/s13280-014-0495-x

Gregory, R., Failing, L., Harstone, M., Long, G., McDaniels, T., and Ohlson, D. (2012). Structured Decision Making: A Practical Guide to Environmental Management Choices. Hoboken, NJ: John Wiley \& Sons.

Hallegatte, S., Shah, A., Lempert, R., Brown, C., and Gill, S. (2012). Investment Decision Making under Deep Uncertainty. Policy Res. working paper World Bank 6193, 1-41. doi:10.1596/1813-9450-6193

Hallett, L. M., Diver, S., Eitzel, M. V., Olson, J. J., Ramage, B. S., Sardinas, H., et al. (2013). Do we Practice what We Preach? Goal Setting for Ecological Restoration. Restor Ecol. 21 (3), 312-319. doi:10.1111/rec.12007 
Hansen, L. J., and Hoffmam, J. R. (2011). Climate Savvy Adapting Conservation and Resource Management to a Changing World. Editors J. R. Hoffman and I NetLibrary. 1st ed. (Washington, DC: Island Press/Center for Resource Economics, Imprint, Island Press).

Harris, J. A., Hobbs, R. J., Higgs, E., and Aronson, J. (2006). Ecological Restoration and Global Climate Change. Restor Ecol. 14 (2), 170-176. doi:10.1111/j.1526100x.2006.00136.x

Harris, R. M. B., Beaumont, L. J., Vance, T. R., Tozer, C. R., Remenyi, T. A., Perkins-Kirkpatrick, S. E., et al. (2018). Biological Responses to the Press and Pulse of Climate Trends and Extreme Events. Nat. Clim Change 8 (7), 579-587. doi:10.1038/s41558-018-0187-9

Hart, B. T. (2016). The Australian Murray-Darling Basin Plan: Challenges in its Implementation (Part 1). Int. J. Water Resour. Dev. 32 (6), 819-834. doi:10. 1080/07900627.2015.1083847

Heller, N. E., and Zavaleta, E. S. (2009). Biodiversity Management in the Face of Climate Change: a Review of 22 Years of Recommendations. Biol. conservation 142 (1), 14-32. doi:10.1016/j.biocon.2008.10.006

Hinkel, J. (2011). "Indicators of Vulnerability and Adaptive Capacity": Towards a Clarification of the Science-Policy Interface. Glob. Environ. Change 21 (1), 198-208. doi:10.1016/j.gloenvcha.2010.08.002

Hobbs, R. J., and Harris, J. A. (2001). Restoration Ecology: Repairing the Earth's Ecosystems in the New Millennium. Restor Ecol. 9 (2), 239-246. doi:10.1046/j. 1526-100x.2001.009002239.x

Hobbs, R. J., and Norton, D. A. (1996). Towards a Conceptual Framework for Restoration Ecology. Restor Ecol. 4 (2), 93-110. doi:10.1111/j.1526-100X.1996. tb00112.x

Horne, A., Webb, A., Stewardson, M., Richter, B., and Acreman, M. (2017b). Water for the Environment: From Policy and Science to Implementation and Management. Cambridge: Academic Press.

Horne, A. C., Konrad, C., Webb, J. A., and Acreman, M. (2017a). "Visions, Objectives, Targets, and Goals," in Water for the Environment (Amsterdam: Elsevier), 189-199. doi:10.1016/b978-0-12-803907-6.00010-3

Horne, A. C., Nathan, R., Poff, N. L., Bond, N. R., Webb, J. A., Wang, J., et al. (2019). Modeling Flow-Ecology Responses in the Anthropocene: Challenges for Sustainable Riverine Management. BioScience 69 (10), 789-799. doi:10.1093/ biosci/biz087

John, A., Nathan, R., Horne, A., Stewardson, M., and Webb, J. A. (2020). How to Incorporate Climate Change into Modelling Environmental Water Outcomes: a Review. J. Water Clim. Change 11 (2), 327-340. doi:10. 2166/wcc. 2020.263

Juhola, S., and Kruse, S. (2015). A Framework for Analysing Regional Adaptive Capacity Assessments: Challenges for Methodology and Policy Making. Mitig Adapt Strateg. Glob. Change 20 (1), 99-120. doi:10.1007/s11027-013-9481-z

Kiem, A. S., Austin, E. K., and Verdon-Kidd, D. C. (2016). Water Resource Management in a Variable and Changing Climate: Hypothetical Case Study to Explore Decision Making under Uncertainty. J. Water Clim. Change 7 (2), 263-279. doi:10.2166/wcc.2015.040

King, J., and Brown, C. (2010). Integrated basin Flow Assessments: Concepts and Method Development in Africa and South-East Asia. Freshw. Biol. 55 (1), 127-146. doi:10.1111/j.1365-2427.2009.02316.x

King, J. M., Tharme, R. E., and De Villiers, M. (2000). Environmental Flow Assessments for Rivers: Manual for the Building Block Methodology. Pretoria: Water Research Commission.

Koehn, J. D., Hobday, A. J., Pratchett, M. S., and Gillanders, B. M. (2011). Climate Change and Australian marine and Freshwater Environments, Fishes and Fisheries: Synthesis and Options for Adaptation. Mar. Freshw. Res. 62 (9), 1148-1164. doi:10.1071/mf11139

Ladson, A., and Finlayson, B. (2002). Rhetoric and Reality in the Allocation of Water to the Environment: a Case Study of the Goulburn River, Victoria, Australia. River Res. Applic. 18 (6), 555-568. doi:10.1002/rra.680

Lin, B. B., and Petersen, B. (2013). Resilience, Regime Shifts, and Guided Transition under Climate Change: Examining the Practical Difficulties of Managing Continually Changing Systems. Ecol. Soc. 18 (1), 28. doi:10.5751/es-05128180128

Mastrandrea, M. D., Heller, N. E., Root, T. L., and Schneider, S. H. (2010). Bridging the gap: Linking Climate-Impacts Research with Adaptation Planning and Management. Climatic Change 100 (1), 87-101. doi:10.1007/s10584-010$9827-4$
Mezger, G., De Stefano, L., and González del Tánago, M. (2019). Assessing the Establishment and Implementation of Environmental Flows in Spain. Environ. Manage. 64 (6), 721-735. doi:10.1007/s00267-019-01222-2

Milly, P. C. D., Betancourt, J., Falkenmark, M., Hirsch, R. M., Kundzewicz, Z. W., Lettenmaier, D. P., et al. (2008). Stationarity Is Dead: Whither Water Management? Science 319 (5863), 573-574. doi:10.1126/science.1151915

Morrongiello, J. R., Beatty, S. J., Bennett, J. C., Crook, D. A., Ikedife, D. N. E. N., Kennard, M. J., et al. (2011). Climate Change and its Implications for Australia's Freshwater Fish. Mar. Freshw. Res. 62 (9), 1082-1098. doi:10.1071/mf10308

Nel, J. L., Turak, E., Linke, S., and Brown, C. (2011). Integration of Environmental Flow Assessment and Freshwater Conservation Planning: A New Era in Catchment Management. Mar. Freshw. Res. 62 (3), 290-299. doi:10.1071/ mf09318

OEH (2014). Murray Murrumbidgee Climate Change Snapshot. Sydney: OEH.

Pahl-Wostl, C., Arthington, A., Bogardi, J., Bunn, S. E., Hoff, H., Lebel, L., et al. (2013). Environmental Flows and Water Governance: Managing Sustainable Water Uses. Curr. Opin. Environ. Sustainability 5 (3-4), 341-351. doi:10.1016/j. cosust.2013.06.009

Palmer, M. A., Lettenmaier, D. P., Poff, N. L., Postel, S. L., Richter, B., and Warner, R. (2009). Climate Change and River Ecosystems: protection and Adaptation Options. Environ. Manag. 44 (6), 1053-1068. doi:10.1007/ s00267-009-9329-1

Palmer, M. A., Reidy Liermann, C. A., Nilsson, C., Flörke, M., Alcamo, J., Lake, P. S., et al. (2008). Climate Change and the World's River Basins: Anticipating Management Options. Front. Ecol. Environ. 6 (2), 81-89. doi:10.1890/060148

Pielke, R. A., Wilby, R., Niyogi, D., Hossain, F., Dairuku, K., Adegoke, J., et al. (2012). Dealing with Complexity and Extreme Events Using a Bottom-Up, Resource-Based Vulnerability Perspective. Extreme Events Nat. Hazards: Complexity Perspective, Geophys. Monogr. Ser 196, 345-359. doi:10.1029/ $2011 \mathrm{gm} 001086$

Pittock, J., Williams, J., and Grafton, R. Q. (2015). The Murray-Darling Basin Plan Fails to deal Adequately with Climate Change. Water 42, 28-34. doi:10.3316/ informit.603377005698763

Poff, N. L., Allan, J. D., Bain, M. B., Karr, J. R., Prestegaard, K. L., Richter, B. D., et al. (1997). The Natural Flow Regime. BioScience 47 (11), 769-784. doi:10. 2307/1313099

Poff, N. L. (2017). Beyond the Natural Flow Regime? Broadening the HydroEcological Foundation to Meet Environmental Flows Challenges in a Nonstationary World. Freshw. Biol. 63 (8), 1011-1021. doi:10.1111/fwb.13038

Prober, S. M., Thiele, K. R., Rundel, P. W., Yates, C. J., Berry, S. L., Byrne, M., et al. (2012). Facilitating Adaptation of Biodiversity to Climate Change: a Conceptual Framework Applied to the World's Largest Mediterranean-Climate woodland. Climatic Change 110 (1-2), 227-248. doi:10.1007/s10584-011-0092-y

Prober, S. M., Williams, K. J., Broadhurst, L. M., and Doerr, V. A. (2018). Nature Conservation and Ecological Restoration in a Changing Climate: what Are We Aiming for? Rangeland J. 39 (6), 477-486.

Prober, S. M., and Dunlop, M. (2011). Climate Change: a Cause for New Biodiversity Conservation Objectives but Let's Not Throw the Baby Out with the Bathwater. Ecol. Manage. Restoration 12 (1), 2-3. doi:10.1111/j. 1442-8903.2011.00563.x

Saft, M., Peel, M. C., Western, A. W., Perraud, J. M., and Zhang, L. (2016). Bias in Streamflow Projections Due to Climate-induced Shifts in Catchment Response. Geophys. Res. Lett. 43 (4), 1574-1581. doi:10.1002/2015gl067326

Sharma, J., and Ravindranath, N. H. (2019). Applying IPCC 2014 Framework for hazard-specific Vulnerability Assessment under Climate Change. Environ. Res. Commun. 1 (5), 051004. doi:10.1088/2515-7620/ab24ed

Shenton, W., Bond, N. R., Yen, J. D. L., and Mac Nally, R. (2012). Putting the "Ecology" into Environmental Flows: Ecological Dynamics and Demographic Modelling. Environ. Manag. 50 (1), 1-10. doi:10.1007/s00267-012-9864-z

Smakhtin, V., Revenga, C., and Döll, P. (2004). A Pilot Global Assessment of Environmental Water Requirements and Scarcity. Water Int. 29 (3), 307-317. doi:10.1080/02508060408691785

Stein, B. A., Staudt, A., Cross, M. S., Dubois, N. S., Enquist, C., Griffis, R., et al. (2013). Preparing for and Managing Change: Climate Adaptation for Biodiversity and Ecosystems. Front. Ecol. Environ. 11 (9), 502-510. doi:10. $1890 / 120277$

Tear, T. H., Kareiva, P., Angermeier, P. L., Comer, P., Czech, B., Kautz, R., et al. (2005). How Much Is Enough? the Recurrent Problem of Setting Measurable 
Objectives in Conservation. BioScience 55 (10), 835-849. doi:10.1641/00063568(2005)055[0835:hmietr]2.0.co;2

Tharme, R. E. (2003). A Global Perspective on Environmental Flow Assessment: Emerging Trends in the Development and Application of Environmental Flow Methodologies for Rivers. River Res. Appl. 19 (5-6), 397-441. doi:10.1002/ rra.736

Thompson, L. M., Lynch, A. J., Beever, E. A., Engman, A. C., Falke, J. A., Jackson, S. T., et al. (2021). Responding to Ecosystem Transformation: Resist, Accept, or Direct? Fisheries 46 (1), 8-21. doi:10.1002/fsh.10506

Tonkin, J. D., Merritt, D. M., Olden, J. D., Reynolds, L. V., and Lytle, D. A. (2018). Flow Regime Alteration Degrades Ecological Networks in Riparian Ecosystems. Nat. Ecol. Evol. 2 (1), 86-93. doi:10.1038/s41559-017-0379-0

Tonkin, J. D., Poff, N. L., Bond, N. R., Horne, A., Merritt, D. M., Reynolds, L. V., et al. (2019). Prepare River Ecosystems for an Uncertain Future. Nature 570, 301-303. doi:10.1038/d41586-019-01877-1

Victorian Department of Environment (2019). Water and Planning 2019, Victoria's Climate Science Report 2019. Melbourne: Victorian Department of Environment.

Vörösmarty, C. J., Green, P., Salisbury, J., and Lammers, R. B. (2000). Global Water Resources: Vulnerability from Climate Change and Population Growth. Science 289 (5477), 284-288. doi:10.1126/science.289.5477.284

Vörösmarty, C. J., McIntyre, P. B., Gessner, M. O., Dudgeon, D., Prusevich, A., Green, P., et al. (2010). Global Threats to Human Water Security and River Biodiversity. Nature 467 (7315), 555-561. doi:10.1038/nature09440

Watts, R. J., Dyer, F., Frazier, P., Gawne, B., Marsh, P., Ryder, D. S., et al. (2020). Learning from Concurrent Adaptive Management in Multiple Catchments within a Large Environmental Flows Program in Australia. River Res. Applic 36 (4), 668-680. doi:10.1002/rra.3620

West, J. M., Julius, S. H., Kareiva, P., Enquist, C., Lawler, J. J., Petersen, B., et al. (2009). U.S. Natural Resources and Climate Change: Concepts and Approaches for Management Adaptation. Environ. Manag. 44 (6), 1001-1021. doi:10.1007/ s00267-009-9345-1

Wilson, K. A., Carwardine, J., and Possingham, H. P. (2009). Setting Conservation Priorities. Ann. N Y Acad. Sci. 1162 (1), 237-264. doi:10.1111/j.1749-6632.2009. 04149.x

Wilson, K. A., and Law, E. A. (2016). Ethics of Conservation Triage. Front. Ecol. Evol. 4, 112. doi:10.3389/fevo.2016.00112

Yarnell, S. M., Petts, G. E., Schmidt, J. C., Whipple, A. A., Beller, E. E., Dahm, C. N., et al. (2015). Functional Flows in Modified Riverscapes: Hydrographs, Habitats and Opportunities. BioScience 65 (10), 963-972. doi:10.1093/biosci/biv102

Young, W., Bond, N., Brookes, J., Gawne, B., and Jones, G. (2011). Science Reivew of the Estimation of an Environmentally Sustainable Level of Take for the MurrayDarling Basin CSIRO Water. Canberra: CSIRO.

Conflict of Interest: The authors declare that the research was conducted in the absence of any commercial or financial relationships that could be construed as a potential conflict of interest.

Publisher's Note: All claims expressed in this article are solely those of the authors and do not necessarily represent those of their affiliated organizations, or those of the publisher, the editors, and the reviewers. Any product that may be evaluated in this article, or claim that may be made by its manufacturer, is not guaranteed or endorsed by the publisher.

Copyright $\odot 2022$ Judd, Bond and Horne. This is an open-access article distributed under the terms of the Creative Commons Attribution License (CC BY). The use, distribution or reproduction in other forums is permitted, provided the original author(s) and the copyright owner(s) are credited and that the original publication in this journal is cited, in accordance with accepted academic practice. No use, distribution or reproduction is permitted which does not comply with these terms. 